\title{
Deep storage of oceanic crust in a vigorously convecting mantle
}

\author{
J. P. Brandenburg ${ }^{1}$ and P. E. van Keken ${ }^{1}$ \\ Received 20 October 2006; accepted 12 February 2007; published 8 June 2007.
}

[1] Fractionated isotopic ratios in some oceanic basalts indicates the presence of recycled oceanic crust in the mantle. This crust must have escaped complete remixing for a significant period of time. Gravitational settling into a dense layer at the base of the mantle may facilitate this preservation. Christensen and Hofmann (1994) first demonstrated the dynamics of this process by developing scaling laws for extrapolating low convective vigor models to conditions estimated for the mantle. Here this sequestration is studied in models with more Earth-like convective vigor. Scaling laws for geodynamic parameters are updated and the isotopic evolution of the $\mathrm{U}-\mathrm{Pb}$ and $\mathrm{Sm}-\mathrm{Nd}$ systems examined.

Significant accumulation is still found at high Rayleigh number, but only when the excess density of oceanic crust in the lower mantle is larger than currently suggested from laboratory experiments. These accumulations are found to maintain the fractionated isotopic signature of ancient crust for models with moderate to moderately high convective vigor relative to mantle estimates. At the highest convective vigor tested, the accumulations are not isotopically distinct.

Citation: Brandenburg, J. P., and P. E. van Keken (2007), Deep storage of oceanic crust in a vigorously convecting mantle, J. Geophys. Res., 112, B06403, doi:10.1029/2006JB004813.

\section{Introduction}

[2] Analysis of oceanic basalts has revealed considerable isotopic heterogeneity in the mantle [e.g., Zindler and Hart, 1986; Hofmann, 2004]. This may reflect geochemically distinct mantle domains [Zindler and Hart, 1986; Hart, 1988], small distributed anomalies [Phipps-Morgan and Morgan, 1999] or heterogeneity at both the large and small scale [Hofmann, 2004]. Much of this heterogeneity may be due to incomplete remixing of oceanic crust and associated residuum [Hofmann and White, 1982; Silver et al., 1988; Carlson, 1994; van Keken et al., 2002].

[3] The HIMU (High- $\mu$, where $\mu={ }^{238} \mathrm{U} /{ }^{204} \mathrm{~Pb}$ ) and DMM (the depleted mid-ocean ridge basalt (MORB) mantle source) end-members of the mantle isotopic mixing array [Zindler and Hart, 1986] are best explained in this context. HIMU mantle is characterized by high ${ }^{206} \mathrm{~Pb},{ }^{208} \mathrm{~Pb}$ to ${ }^{204} \mathrm{~Pb}$ isotopic ratios relative to bulk-Earth estimates. This indicates a past $\mathrm{U}$,Th enrichment or $\mathrm{Pb}$ depletion. Extraction of oceanic crust is likely the source of U,Th enrichment [Hofmann, 2004]. However, the entire cycle of creation, interaction with seawater and subduction may be responsible for the loss of $\mathrm{Pb}$. Removal of $\mathrm{Pb}$ to the core has also been proposed, but is less probable than purely crustal processes [e.g., Newsom et al., 1986]. Owing to the relatively slow decay of $\mathrm{U}$ and $\mathrm{Th}$, the $\mathrm{Pb}$ isotopic ratios indicate a storage time on the order of $1 \mathrm{Byr}$.

\footnotetext{
${ }^{1}$ Department of Geological Science, University of Michigan, Ann Arbor, Michigan, USA.

Copyright 2007 by the American Geophysical Union. 0148-0227/07/2006JB004813\$09.00
}

[4] A number of conceptual models have been proposed to explain the isolation of HIMU mantle [Hofmann and White, 1982; Davies, 1984; Kellogg et al., 1999; Tackley, 2000]. Many of these models invoke gravitational settling of subducted crust. This may lead to accumulation of a dense layer at the core-mantle boundary. A HIMU isotopic signature evolved in such a layer could then be sampled by thermal plumes [Hofmann and White, 1982]. Upon subduction the crustal basalt will be metamorphosed to eclogite. Owing to elevated garnet content, this eclogite is likely the densest upper mantle assemblage [Irifune and Ringwood, 1993; Poli and Schmidt, 2002]. Recent results have confirmed this upper mantle behavior, and indicate that the excess density may be considerably greater than originally predicted [Aoki and Takahashi, 2004]. Below the transition zone, the mineral assemblage of the crust will eventually convert to a perovskite assemblage that may still be denser than the ambient mantle [Kesson et al., 1994; Ono et al., 2001; Hirose et al., 2005]. Phase transitions in the crust may be delayed causing temporary positive buoyancy in the transition zone [Irifune and Ringwood, 1993; van Keken et al., 1997]. However, this does not necessarily prevent crust from penetrating into the lower mantle [Christensen, 2001]. Following the convention of Christensen and Hofmann [1994] we collectively refer to all mineral assemblages derived from subducted oceanic crust as eclogite.

[5] The geodynamics and geochemistry of this crustal segregation were first modeled dynamically by Christensen and Hofmann [1994] (hereafter indicated as CH94). The authors created a 2D model where two convergent plates meet at a migrating downwelling. Isotope composition and chemical density were tracked with two sets of tracers and 
partial melting was simulated at two zones of divergence. The portion of the mantle mixing array between DMM and HIMU was reproduced with proper selection of partition coefficients for $\mathrm{Pb}, \mathrm{U}, \mathrm{Sm}$, and $\mathrm{Nd}$. The dynamics of this study were revisited by Davies [2002] who expanded the kinematic boundary condition to include two convergence zones in a model with an insulating base (pure internal heating) and studied the vertical distribution of chemical density. Davies [2002] did not explicitly model isotopic composition, but did find that a significant amount of old crust pooled at the core-mantle boundary. Xie and Tackley [2004] used the isotopic partitioning formulation from Christensen and Hofmann [1994] in models where nonNewtonian rheology produced plate-like behavior. They further expanded on the treatment of partial melting by linking temperature and pressure to a solidus description [see also Tackley and Xie, 2002], producing a mixing array between DMM- and HIMU-like components. Recently, Davies [2006] found that gravitational settling of eclogitic material could both deplete the upper mantle and lead to the development of a dense layer at the base of a hot, young mantle. The use of kinematic boundary conditions from CH94 and Davies [2002, 2006] has the potential to influence the dynamics of the model by artificially driving or retarding convection. In order to ensure the presence of consistent spreading centers we also employ a kinematic boundary condition. To minimize any interference with convection, we develop a new scaling for the applied velocity by using the force-balance method [e.g., Gable et al., 1991; King et al., 1992]. We find this to be a useful improvement over strict kinematic boundary conditions or the use of a finite yield strength rheology which can cause abrupt changes in tectonic style. Davies [2002] and Xie and Tackley [2004] include the cooling of the mantle in their calculations, which leads to an initially high rate of convective turnover. However, the inclusion of thermal evolution necessitates the selection of an appropriate initial condition. To avoid this complication, our models are computed from a thermal quasi steady state following a spin up period in which the influences of the initial conditions dissipate completely. Our principal aim is to investigate the role of crustal segregation for the maintenance of a HIMU component in the mantle convecting at present-day tectonic velocities. We do so by systematically extending and improving on the results of CH94 who first used this approach.

[6] Computational limitations in 1994 lead Christensen and Hofmann [1994] to evaluate the dynamics at reduced velocities, heat flow and temporal variability (these three properties hereafter referred to as "convective vigor") by limiting the thermal Rayleigh number to moderately low values. By time scaling, the results were extrapolated to present-day tectonic velocities. However, the nonlinear behavior of thermal convection increases with convective vigor, and increases more strongly for thermochemical convection. Extrapolation from lower convective vigor may overlook the highly time-dependent nature of these effects. We begin with a detailed reproduction of CH94's base model, which verifies our computational methods and reveals a high level of model sensitivity to the scaling of chemical relative to thermal buoyancy. The model is then systematically modified to more Earth-like conditions. The relative proportion of internal heating is increased, a variation of the thermal diffusivity introduced, and the viscosity law is modified to include a stronger stepwise increase at $670 \mathrm{~km}$ depth. The temporal duration is chosen so that each model is effectively integrated over 3.6 Byr. This value, similar to that used in $\mathrm{CH} 94$, is a reasonable approximation for the start of present-day plate tectonics [Zegers and van Keken, 2001]. CH94 also found that this reduced duration is necessary in order to produce isotopic array slopes consistent with observations. The need for this correction reflects uncertainty in the behavior of $\mathrm{Pb}$ in the crust-mantle system, particularly early in the evolution of the Earth. We acknowledge this uncertainty, but retain the isotopic modeling methods of CH94. This provides an independently calibrated basis for evaluating variability that arises from uncertain dynamic parameters.

\section{Methods}

[7] We model the thermochemically convecting mantle as an incompressible Boussinesq fluid at infinite Prandtl number. For this, we solve the coupled mass-conservation, Stokes and heat advection-diffusion equations in nondimensional form. Respectively, these are

$$
\begin{gathered}
\nabla \cdot \mathbf{u}=0, \\
-\nabla P+\nabla \cdot(\eta \underline{\dot{\epsilon}})=[\operatorname{RaT} \alpha(z)-\operatorname{RcC} \beta(z)] \hat{\mathbf{g}}, \\
\frac{\partial T}{\partial t}+(\mathbf{u} \cdot \nabla) T=\nabla \cdot(\kappa(z) \nabla T)+Q,
\end{gathered}
$$

where $\mathbf{u}$ is the velocity vector, $P$ the dynamic pressure, $T$ the temperature, $\hat{\mathbf{g}}$ the unit vector in the direction of gravity, $\alpha$ the thermal expansivity, $\beta$ the generalized chemical compressibility, and $\kappa$ the thermal diffusivity. $Q$ is the volumetric internal heating normalized by density and heat capacity. $\dot{\epsilon}$ is the strain rate tensor $\left(\nabla \mathbf{u}+\nabla \mathbf{u}^{T}\right) . R a$ is the thermal Rayleigh number,

$$
R a=\frac{\rho_{o} g \alpha_{o} \Delta T h^{3}}{\eta_{o} \kappa_{o}},
$$

where $\rho_{o}$ and $\kappa_{o}$ are the surface density and thermal diffusivity. $\alpha_{o}$ and $\eta_{o}$ are the average thermal expansivity and viscosity. For reference values, see Table $1 . R c$ is the buoyancy Rayleigh number,

$$
R c=\frac{\rho_{o} g \beta_{o} \Delta C h^{3}}{\kappa_{o} \eta_{o}}
$$

where $C$ is the phase function defining the local concentration of the eclogite component (section 2.1.1) and $\beta_{o}$ is the average chemical compressibility. The effects of hydrostatic pressure are included by allowing $\alpha$ and $\beta$ to vary as a function of depth,

$$
\alpha(z)=\frac{d}{1-e^{-d}} \cdot e^{-d z} \quad \beta(z)=\frac{s}{1-e^{-s}} \cdot e^{-s z} .
$$


Table 1. Dynamic Variables and Reference Values

\begin{tabular}{|c|c|c|}
\hline Quantity & Variable & Nondimensionalization $^{a}$ \\
\hline $\begin{array}{l}\text { Length } \\
\text { Time }^{b} \\
\text { Time }^{c} \\
\text { Volumetric heat production }\end{array}$ & $\begin{array}{l}l \\
t \\
t \\
Q\end{array}$ & $\begin{array}{c}l^{\prime}=l h^{\prime} \\
t^{\prime}=t\left(h^{\prime 2} / \kappa^{\prime}{ }_{o}\right) \\
t^{\prime}=t u_{o} \tau^{\prime} \\
Q^{\prime}=Q\left(k_{o}^{\prime} \Delta T_{o}^{\prime} / h^{\prime 2}\right)\end{array}$ \\
\hline Quantity & Constant & Reference Value \\
\hline $\begin{array}{l}\text { Thickness } \\
\text { Thermal diffusivity } \\
\text { Transit time } \\
\text { Viscosity } \\
\text { Temperature contrast } \\
\text { Thermal expansivity }\end{array}$ & $\begin{array}{c}h^{\prime} \\
\kappa_{o}^{\prime} \\
\tau^{\prime} \\
\eta_{o}^{\prime} \\
\Delta T_{o}^{\prime} \\
\alpha_{o}^{\prime} \\
\end{array}$ & $\begin{array}{c}2885 \mathrm{~km} \\
10^{-6} \mathrm{~m}^{2} / s \\
60 \mathrm{Myr} \\
10^{22} \mathrm{~Pa} \cdot s \\
3000 \mathrm{~K} \\
3 \cdot 10^{-5} \mathrm{~K}^{-1} \\
\end{array}$ \\
\hline
\end{tabular}

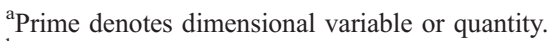

${ }^{\mathrm{b}}$ Diffusional timescale.

${ }^{\mathrm{c}}$ Transit timescale.

Since thermal and chemical buoyancy act only in the vertical direction, the ratio between $R a$ and $R c$ is used to scale the dynamic behavior of density anomalies. This quantity is called the phase buoyancy ratio,

$$
R \rho(z)=\frac{R c \beta(z)}{\operatorname{Ra\alpha }(z)} .
$$

$R_{\rho}$ is conserved so that the relative strength of chemical buoyancy stays the same as the thermal Rayleigh number is varied. The variation with depth of $\alpha, \beta$ and $R_{\rho}$ for the standard case (STD) of CH94 is shown in Figure 1a.

\subsection{Implementation}

[8] Equations (1)-(3) are solved by a finite element method based on the SEPRAN package [Segal and Praagman, 1995]. The Stokes equations are solved on a two dimensional triangular mesh with quadratic elements, while the heat advection-diffusion equations are solved on a mesh with nested linear elements. A penalty function method is used to eliminate dynamic pressure from the Stokes equations. The model domain is an aspect ratio four box. Vertical resolution of the quadratic mesh is approximately $80 \mathrm{~km}$ in the interior of the model, with strong refinement to approximately $10 \mathrm{~km}$ at the surface and $2 \mathrm{~km}$ at the base. Horizontal resolution is uniform and approximately $80 \mathrm{~km}$. For the heat advection-diffusion equations the top and bottom boundary conditions are isothermal and side boundary conditions are insulating. For the Stokes equations the side and bottom boundaries are free-slip. We impose variable horizontal velocity as a boundary condition at the top of the model. This kinematic boundary condition is similar to $\mathrm{CH} 94$ and is a simple approximation to plate-like behavior with a migrating trench. The applied kinematic velocity is prescribed by

$$
u(x, t)= \pm u_{o}+\frac{\pi u_{o}}{10} \sin \left(\frac{\pi u_{o}}{5} t\right)
$$

The position of the trench $x_{c}$ is given by

$$
x_{c}=2+\cos \left(\frac{\pi u_{o}}{5} t\right)
$$

where $u_{o}$ is the average surface velocity (section 2.3). This implementation has been successfully tested against existing benchmarks [Blankenbach et al., 1989; van Keken et al., 1997].

\subsubsection{Chemical Buoyancy}

[9] The chemical density field is approximated as a binary mixture discretized to only the active tracers. A second set of passive tracers is used exclusively for isotope modeling, and is not included in the calculation of chemical buoyancy. In this approximation peridotite is treated as a mixture of $12.5 \%$ eclogite and $87.5 \%$ harzburgite. Each active tracer carries a small excess density and locally contributes to the body force in the direction of gravity. Areas of the model domain containing no active tracers are affected by only thermal buoyancy. This concentration of active tracers $(C=0.0)$ implicitly represents harzbugitic mantle, and by virtue of having no negative chemical buoyancy is the lightest material in these models. Where the active tracers fill $12.5 \%$ of the volume, the composition is equivalent to undifferentiated peridotite. Peridotite has a small negative density, and is used as the reference concentration $\left(C_{\text {peridotite }}=0.125\right)$. Any portion of the model domain where the concentration of active tracers exceeds 8 times the reference value has an eclogitic composition $(C=1.0)$. The net excess density of all eclogite is distributed among the active tracers as

$$
\Delta \rho=\frac{R c V C_{\text {peridotite }}}{n_{\text {active }}},
$$

A.

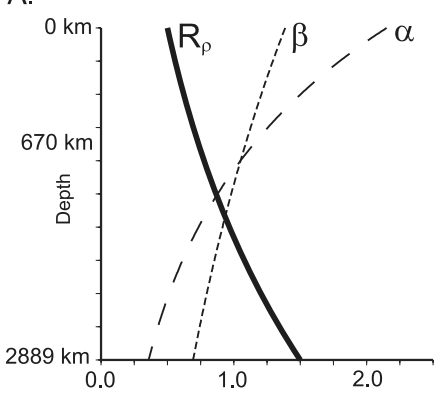

B.
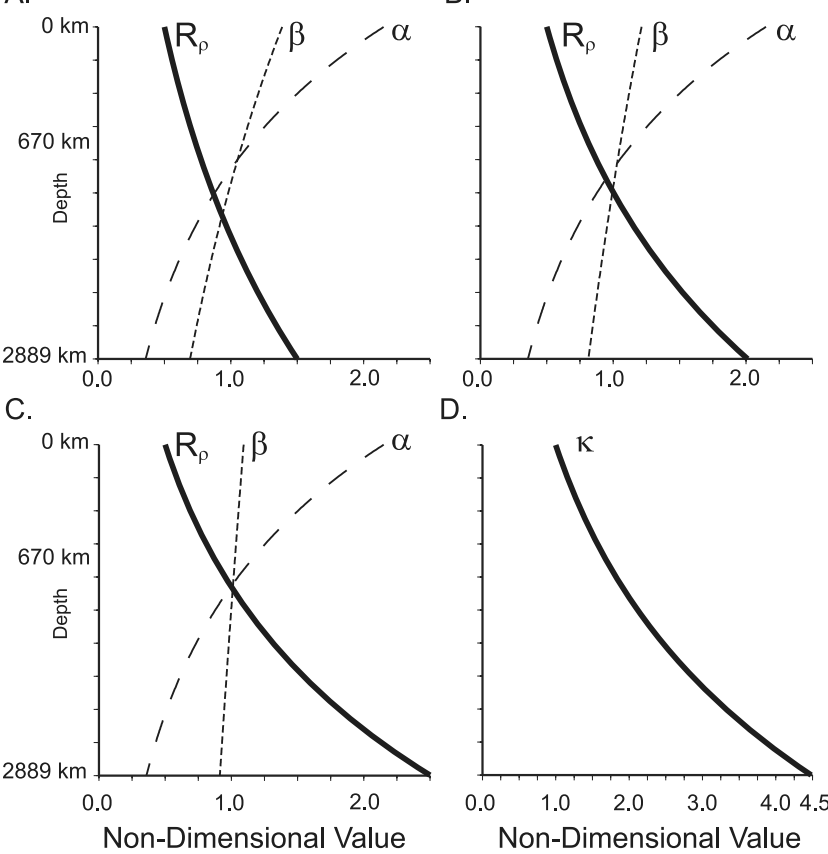

D.

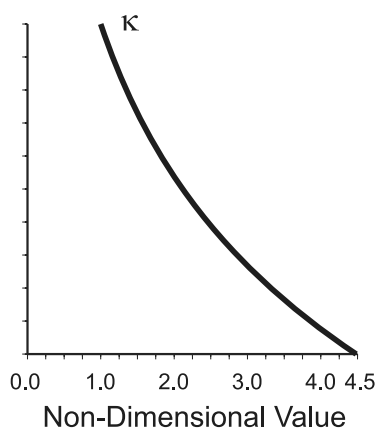

Figure 1. Depth variation in the scaling of compositional buoyancy: (a) Group A, B and CH94 Standard Case $\left(R_{\rho}=\right.$ 1.5 at CMB), (b) Group C $\left(R_{\rho}=2.0\right.$ at CMB), (c) Group D $\left(R_{\rho}=2.5\right.$ at $\left.\mathrm{CMB}\right)$, and $(\mathrm{d})$ variation of thermal expansivity for Group A, B, C, D. 
Table 2. Parameters for Isotope Model

\begin{tabular}{lccc}
\hline Isotope & Initial Condition $^{\mathrm{a}}$ & Final Condition & Partition Coefficient \\
\hline${ }^{204} \mathrm{~Pb}$ & 1.0000 & 1.00000 & 0.150 \\
${ }^{206} \mathrm{~Pb}$ & 11.8651 & 18.500 & 0.150 \\
${ }^{207} \mathrm{~Pb}$ & 13.3313 & 15.500 & 0.150 \\
${ }^{235} \mathrm{U}$ & 2.2330 & 0.0644 & 0.007 \\
${ }^{238} \mathrm{U}$ & 15.5149 & 8.8800 & 0.007 \\
${ }^{147} \mathrm{Sm}$ & 0.2293 & 0.22393 & 0.100 \\
${ }^{143} \mathrm{Nd}$ & 1.0000 & 1.00000 & 0.070 \\
${ }^{144} \mathrm{Nd}$ & 0.5078 & 0.51310 & 0.070 \\
\hline
\end{tabular}

${ }^{\text {a }}$ Relative to ${ }^{204} \mathrm{~Pb}$ or ${ }^{143} \mathrm{Nd}$ as appropriate (after CH94).

where $V$ is the model volume and $n_{\text {active }}$ is the number of active tracers. This is different from the tracer ratio method [Tackley and King, 2003] where the less dense harzburgite is explicitly represented by a second set of tracers with positive chemical buoyancy.

[10] Tracers are advanced within the velocity field by a fourth-order Runge-Kutta method. This high-order scheme is necessary to minimize accumulated error [van Keken et al., 1997]. We solve the heat equation with a time step of twice the Courant-Friedrichs-Levy (CFL) criterion which provides sufficient accuracy for the temperature field. For accurate particle tracing we use $50 \%$ of the CFL time step with interpolated velocity fields. Convergence tests performed on

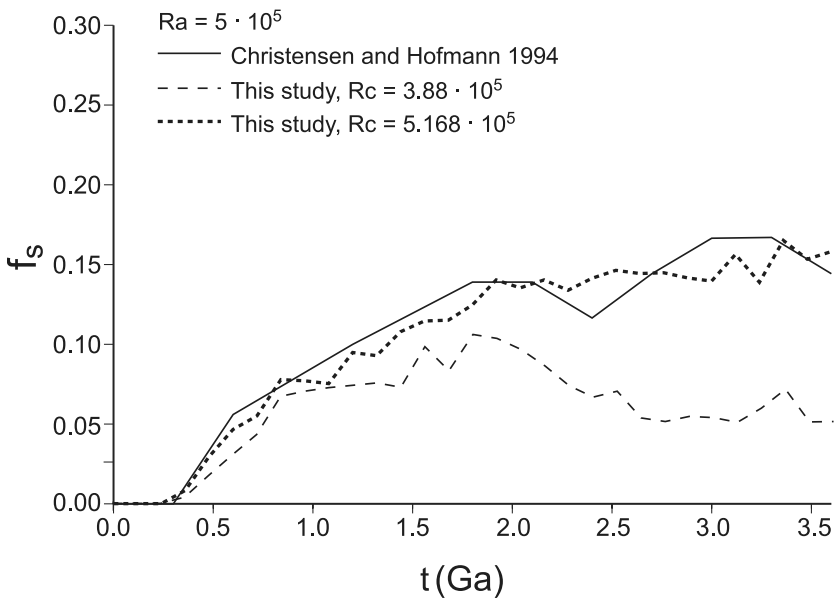

Figure 2. The $\mathrm{f}_{\mathrm{s}}$ time series for $\mathrm{CH} 94$ Standard Case, the initial reproduction $\left(R c=3.88 \cdot 10^{5}\right)$, and the rescaled reproduction $\left(R c=5.168 \cdot 10^{5}\right)$.

the full thermochemical solution and verification with benchmarks [van Keken et al., 1997] confirmed the accuracy of this method.

\subsubsection{Melting}

[11] Mid-ocean ridge partial melting is simulated in rectangular zones at the upper right and left corners of the

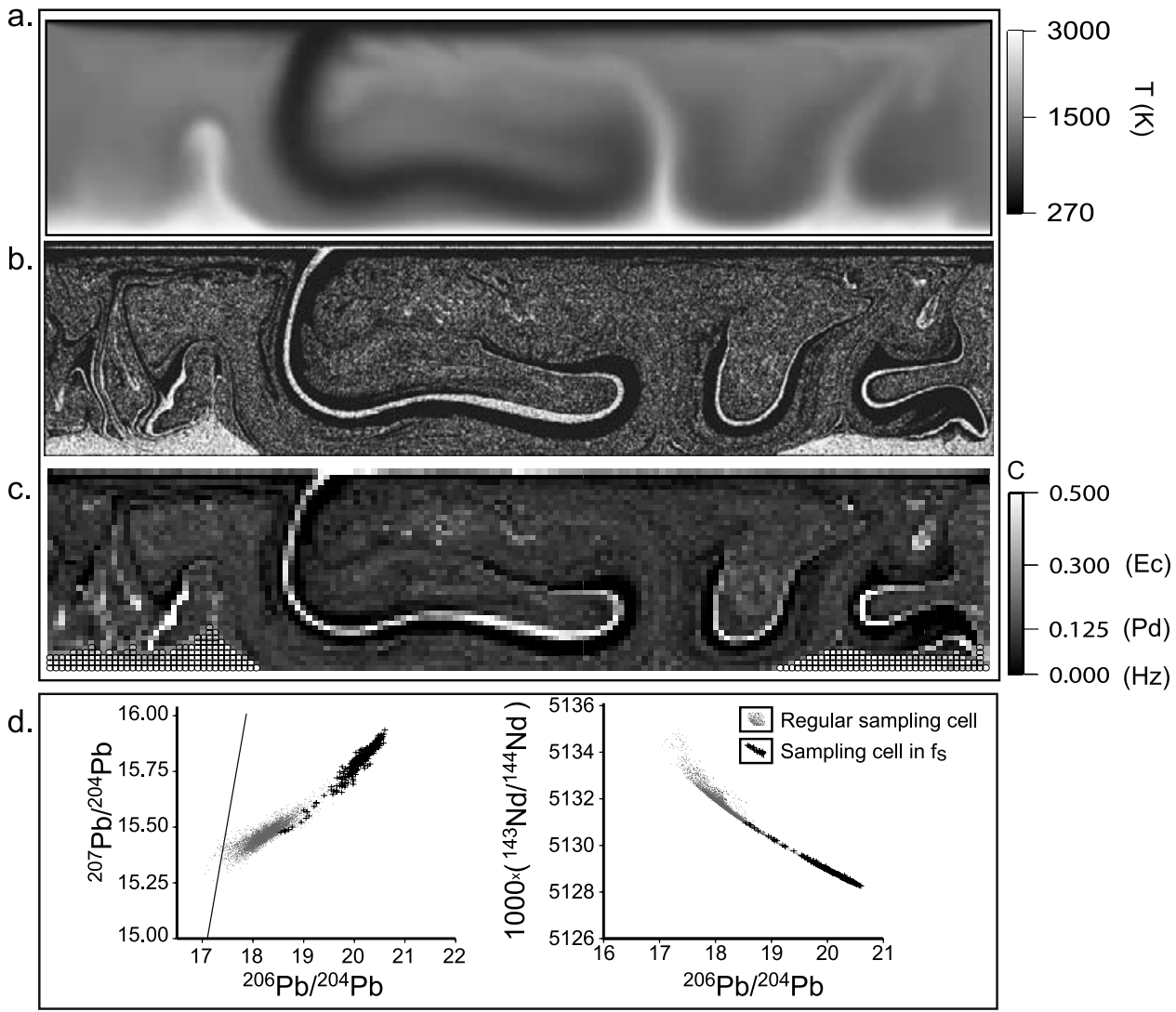

Figure 3. Reproduction of the CH94 Standard model at 3.36 Byr. (a) Temperature, (b) every other active tracer, (c) grid-averaged $\mathrm{C}$ values (the open circles identify grid cells that have $\mathrm{C}>0.3$, and are part of a vertically continuous column), and (d) grid-averaged isotopic chemistry at 3.6 Byr (points labeled $\mathrm{f}_{\mathrm{s}}$ correspond to the cells that contribute to the calculation of $\mathrm{f}_{\mathrm{s}}$ ). 

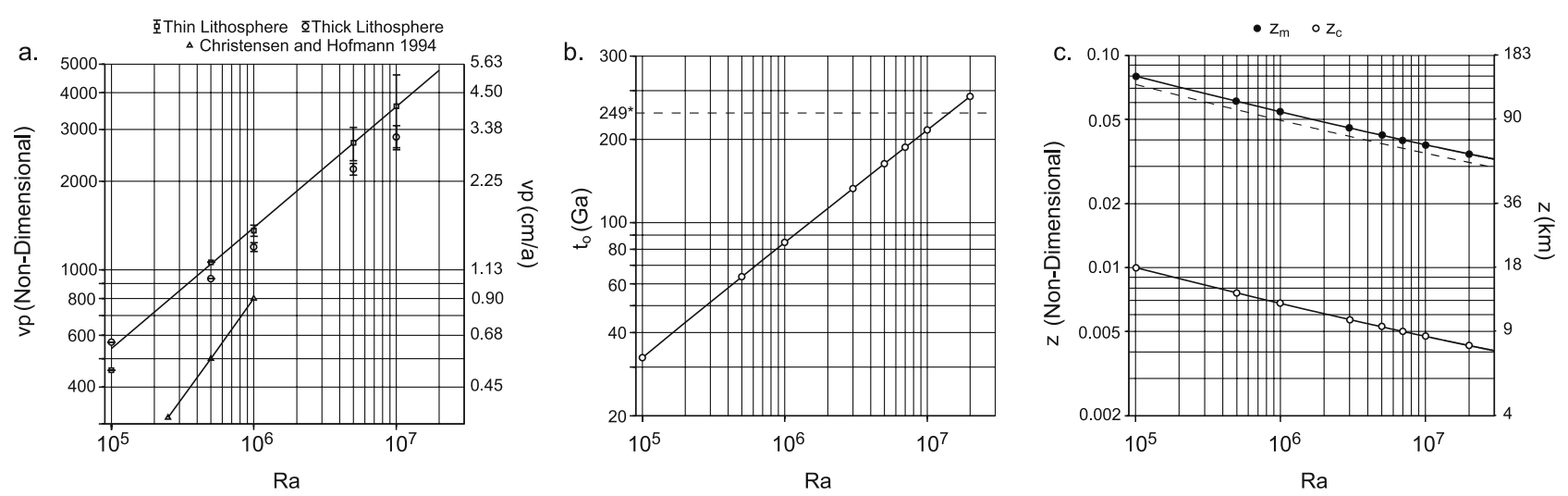

Figure 4. Updated $R a$ scaling laws (a) surface velocity, (b) time, and (c) boundary layer (dashed line), depth of melt extraction $z_{m}$, and thickness of crust $z_{c} ; t_{o}$ is the dimensional time constant: $t^{\prime}=t \cdot t_{o}$.

model domain. Here the kinematic boundary condition ensures uninterrupted ridge-like spreading. The crust formation is modeled by redistributing the active tracers. Any active tracer that crosses vertically into a melting zone is moved to a random depth within a thin, shallow layer. This shallow layer represents the newly created oceanic crust, while the low concentration of active tracers in the rest of the melting zone represents the depleted harzburgite residuum. The thickness of the crust and the dimensions of the melting zone are scaled with the thermal boundary layer thickness (section 2.3).

[12] In addition to the active tracers, a second set of passive tracers is used for modeling isotopic evolution. These tracers are effectively a discretization of the harzburgitic component (in the dynamic calculation, the harzburgitic component is represented by low concentrations or absence of the active eclogite tracers). The passive tracers are introduced as an evenly spaced duplicate of the active tracers at the beginning of the model run, and are not repositioned in the melting zones. For a given time step, radioactive decay of $\mathrm{U}, \mathrm{Sm}$ and the ingrowth of $\mathrm{Pb}, \mathrm{Nd}$ is calculated for all tracers of both sets. The net concentration of isotopic species is then integrated over all of the tracers in each melting zone. Assuming that the melt and residuum are approximately in equilibrium, the integrated concentration of each isotope is repartitioned into the appropriate tracers. We use the batch melting formulation of $\mathrm{CH} 94$ (their equations (13)-(21)). In this formulation, the melt fraction $f$ is determined only by the volume of unmelted eclogite in each melting zone. The time step for the isotope composition is calculated so that on average the incoming flux of eclogite will be consistent with $f \approx 0.125$. This time step is coarser than the time step for the dynamic calculation since accurate particle tracing requires much higher temporal resolution than the calculation of radioactive decay. To prevent artificially extreme fractionation each tracer is flagged once it has experienced partial melting, and cannot be remelted until it has returned to a depth greater than the

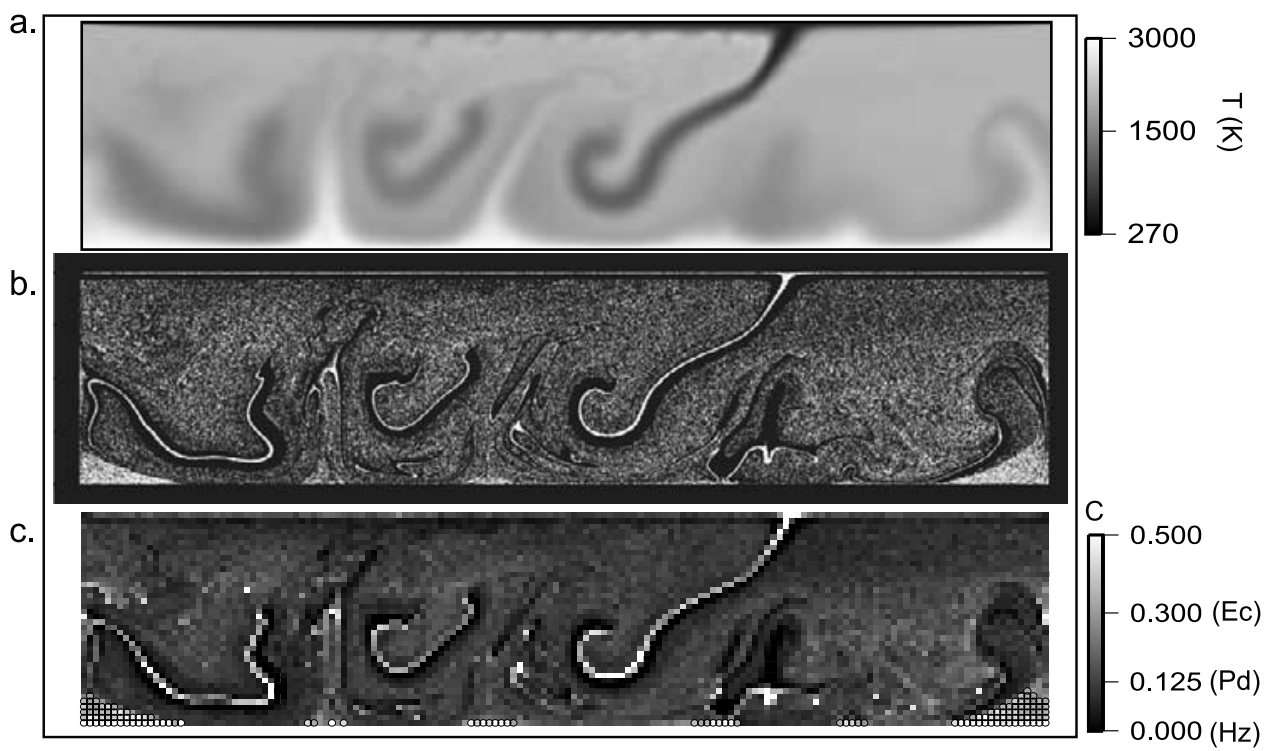

Figure 5. Group D $R a=10^{7}$ run at 3.12 Byr. (a) Temperature, (b) every other active tracer, and (c) gridaveraged $\mathrm{C}$ values. The standard composition for undifferentiated mantle peridotite is $\mathrm{C}=0.125$, and is denoted Pd. Depleted mantle harzburgite is denoted Hz, and enriched eclogite as Ec. 

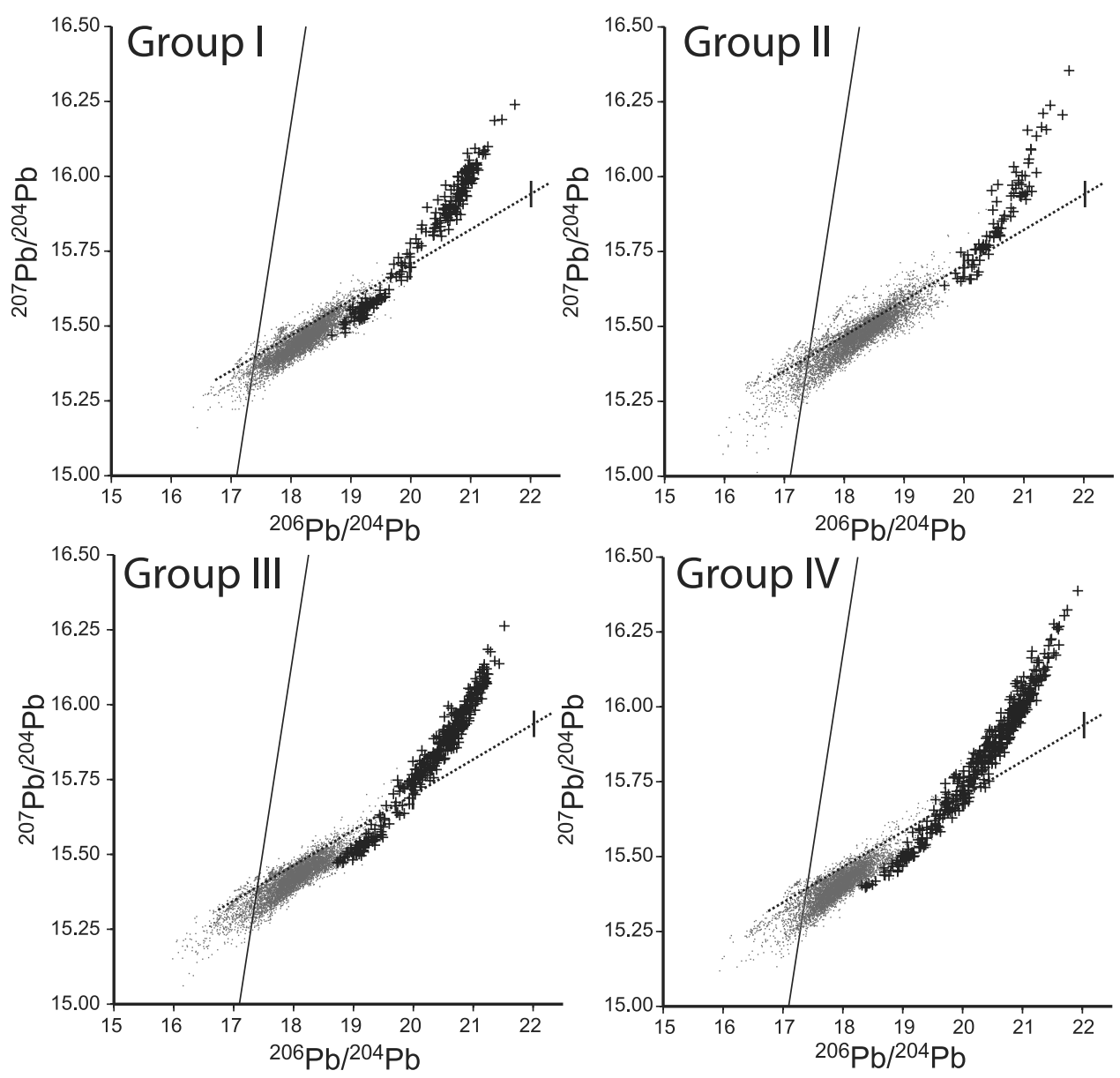

Figure 6. Grid-averaged $\mathrm{Pb}$ isotopes at 3.6 Byr for all $R a=5 \cdot 10^{5}$ runs. The letter on each plot denotes the model group. The thin black line is the Geochron from CH94, the dashed line is the DMM-HIMU mixing line [Hofmann, 2004] with horizontal bars marking the approximate range of HIMU observations. Crosses denotes values from cells contributing to $\mathrm{f}_{\mathrm{s}}$, points denotes all other cells.

lithosphere. As in $\mathrm{CH} 94$, the partition coefficient for $\mathrm{Pb}$ is artificially high. Initial isotope ratios are back-calculated from present-day Bulk Silicate Earth estimates. Values for initial isotope ratios and partitions coefficients are shown in Table 2.

\subsection{Benchmark}

[13] To test the accuracy of our implementation, we reproduce the STD result from CH94 $\left(\mathrm{Ra}=5 \cdot 10^{5}, \mathrm{u}_{\mathrm{o}}=\right.$ $500, \mathrm{R}_{\rho}=1.5$ at the core-mantle boundary $\left.(\mathrm{CMB})\right)$. In this model, viscosity is a smoothly varying function of both temperature and depth,

$$
\eta=\eta_{o} \exp [-b(T-0.5)+c(z-0.5)]
$$

where $b=\ln (65,536)$ and $c=\ln (64)$. Internal heating is prescribed as $Q=2.5$, which leads to a mantle heated approximately $20 \%$ from within and $80 \%$ from below. This configuration results in significantly lower heat flow and surface velocity than estimated values for the mantle. Faced with the limited computational resources of the time, CH94 chose these values since this convective vigor was near the maximum resolvable on their finest mesh. The relatively low velocities in this model are reconciled through the use of transit-time scaling. Rather than scaling time with thermal diffusivity, the nondimensional model time needed for one convective overturn is equated to the overturn time of the mantle,

$$
t^{\prime}=t u_{o} \tau^{\prime},
$$

where $h_{M}^{\prime}$ is the mantle thickness, $u_{p}^{\prime}$ an average terrestrial plate velocity, and $u_{o}$ is from equation (8) (primes denote dimensional quantities). $\tau$ is the characteristic overturn time of the mantle ( $\left.\tau \approx h_{M}^{\prime} / u_{p}^{\prime}=60 \mathrm{Myr}\right)$. The choice of $u_{o}$ is based on surface velocity in an aspect ratio 1 isoviscous calculation with free-slip boundaries. From the values for $d$ and $R_{\rho}$ in CH94, we calculate $R c=3.88 \cdot 10^{5}$ and $s=$ 0.69315 (Figure 1).

[14] Our initial attempts to reproduce the STD model produces similar dynamics, but underestimates the amount of sequestered crust (Figure 2). The rate of accumulation is similar, but the amount of subsequent entrainment is higher in our model. CH94 used $\mathrm{f}_{\mathrm{s}}$ (the total fraction of eclogite found in pools at the core-mantle boundary) and $\left\langle\mathrm{f}_{\mathrm{s}}\right\rangle$ (the time-averaged value) to measure crustal segregation. The model displays similar accumulation in the time series of $\mathrm{f}_{\mathrm{s}}$, but peaks as thicker deposits are swept back into the 

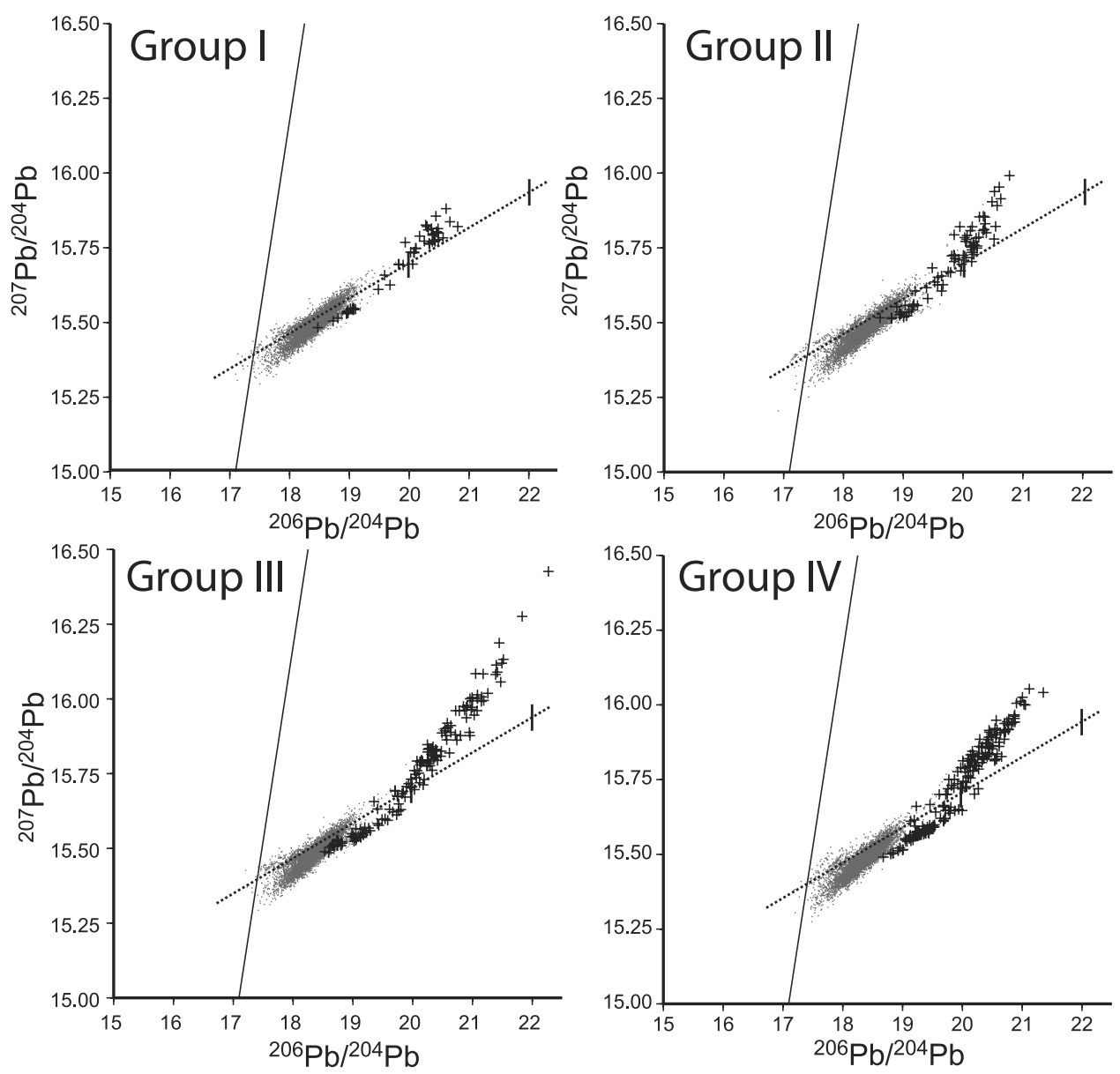

Figure 7. Grid-averaged $\mathrm{Pb}$ isotopes at $3.6 \mathrm{Byr}$ for all $R a=7 \cdot 10^{6}$ runs. The letter on each plot denotes the model group. The thin black line is the Geochron from CH94, the dashed line is the DMM-HIMU mixing line [Hofmann, 2004] with horizontal bars marking the approximate range of HIMU observations. Crosses denotes values from cells contributing to $\mathrm{f}_{\mathrm{s}}$, points denotes all other cells.

convective circulation. In CH94's STD model, $\mathrm{f}_{\mathrm{s}}$ continued to increase gradually.

[15] The isotopic composition is averaged to a sampling grid for output. This same grid is used for the calculation of $\mathrm{f}_{\mathrm{s}}$. Cells in vertically continuous columns with $C>0.3$ starting at the model base are flagged as belonging to the eclogite pools (Figure 3c). CH94 used a $40 \times 20$ grid for this purpose. Other studies have found that the selection of a sampling grid can influence the isotopic mixing arrays produced in this type of model [Xie and Tackley, 2004]. We found that $80 \times 20$ and $40 \times 20$ grids produced spurious fluctuations in the calculation of $\mathrm{f}_{\mathrm{s}}$. Reanalysis of the output on a series of grids with 100 to 10,000 cells revealed that for our 888,000 tracer model, the calculation of $f_{s}$ is only reproducible on grids with approximately 4000 to 10,000 cells. Below 4000 , the cells are larger than many small accumulations at the base of the mode. Above 100,000 the sampling algorithm begins to find the empty space between tracers. Therefore we use a $160 \times 40$ grid (6400 cells) for calculation of $f_{s}$ and isotope arrays (each cell is approximately $72 \mathrm{~km} \times 72 \mathrm{~km}$ ). However, the variability due to the choice of sampling grid is not sufficient to account for the offset in $\left\langle\mathrm{f}_{\mathrm{s}}\right\rangle$.
[16] After consistently observing this offset, we performed an extensive series of tests which included convergence tests and alternative tracer buoyancy formulations, such as the tracer-ratio method [Tackley and King, 2003]. For optimum accuracy in tracer-based density, we use approximately 888,000 active tracers (approximately $6 \mathrm{~km}$ spacing). The same number of tracers is included in the duplicate set. From our experiments with improved resolution we do not find a significant or systematic increase in $\left\langle\mathrm{f}_{\mathrm{s}}\right\rangle$. In a qualitative comparison of temperature fields, the thermal boundary layers seem slightly less diffuse than in CH94. Holding $R c$ constant, we incrementally decrease $R a$ until the amount of sequestered crust is equivalent to STD. This occurs at $R a=4 \cdot 10^{5}$ indicating approximately $20 \%$ offset in the implementation of $R_{\rho}$. Alternatively, this can be achieved at $R a=5 \cdot 10^{5}$ with a $20 \%$ increase in $R c$. CH94 used reference values of $\alpha_{o}$ and $\beta_{o}$ in the calculation of $R_{\rho}$. Our initial assumption was that the ratio of $\alpha_{o}$ to $\beta_{o}$ was 1.0 . We change this ratio to $0.8\left(R c=5.168 \cdot 10^{5}\right)$ and are able to successfully reproduce the $f_{s}$ time series (Figure 2) and isotopic systematics (Figure 3). This change is a small departure from the original $\mathrm{CH} 94$ values. There is not a clear numerical reason for this offset (Ulrich Christensen, personal communication, 2006) since both finite element 

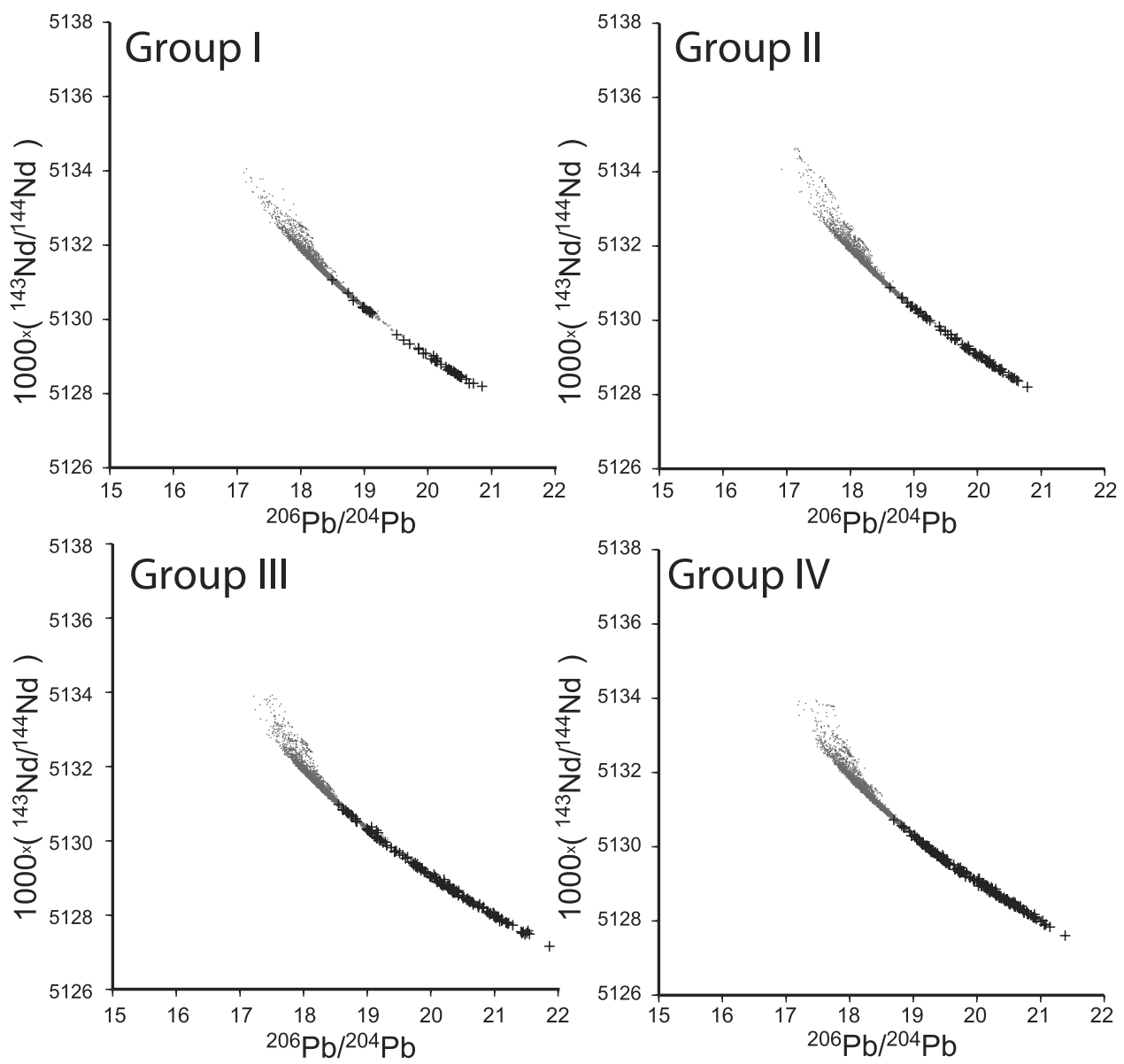

Figure 8. Grid-averaged $\mathrm{Pb}$ and $\mathrm{Nd}$ isotopes at $3.6 \mathrm{Byr}$ for all $\mathrm{Ra}=7 \cdot 10^{6}$ runs. The letter on each plot denotes the model group. Crosses denotes values from cells contributing to $f_{s}$, points denotes all other cells.

implementations compare favorably to each other in a thermochemical benchmark [van Keken et al., 1997]. Therefore the offset seen in our reproduction of CH94 is likely due to a simple scalar offset in $\alpha$ or $\beta$. This reflects the inherently high sensitivity of the $\left\langle f_{s}\right\rangle$ measurement to small changes in model parameters.

\subsection{Scaling of Dynamic Parameters}

[17] On the basis of the behavior of their STD model over a small range of $\mathrm{Ra}, \mathrm{CH} 94$ developed a scaling relationships for $\left\langle f_{s}\right\rangle$. In the standard case, $\left\langle f_{s}\right\rangle=0.144$ and from scaling analysis behaves as $\left\langle\mathrm{f}_{\mathrm{s}}\right\rangle \propto R a^{-\frac{2}{3}}$. This predicts that at more Earth like convective vigor $\left(R a \approx 10^{7}\right)\left\langle\mathrm{f}_{\mathrm{s}}\right\rangle \approx 0.02$. The behavior of the accumulated layer will be determined by input from subducted crust and entrainment by thermal plumes, both of which become progressively more timedependent with increasing $R a$. This time dependence is further enhanced by a higher internal heating. To investigate these effects, we increase the amount of internal heating to $Q=7.5$ and test a set of higher $R a$. This results in models that are approximately $80 \%$ heated from within and $20 \%$ from below at the lowest vigor investigated $\left(R a=10^{5}\right)$ and equally from within and below at the highest $\left(R a=2 \cdot 10^{7}\right)$. The possible effects of basal heating on this type of model were discussed by Davies [2002], who circumvented the issue by using a model with purely internal heating.
[18] The scaling of many variables in this model depends on $R a$ and on the choice of the kinematic plate velocity $u_{o}$. A sufficient convective vigor is reached when $u_{o}$ and surface heat flow reach Earth-like values. Melting in the isotopic fractionation model must be compatible with the heat flow, which is a function of boundary layer thickness. Ideally, $u_{o}$ is chosen so that convective flow is neither driven or hindered by the kinematic boundary condition. Boundary layer analysis [e.g., Turcotte and Schubert, 2002] predicts that $u_{o} \propto R^{a^{\frac{2}{3}}}$ in isoviscous convection in an aspect ratio 1 box. This estimate ignores both the influence of aspect ratio (which is on average equal to 2 in these models) and the effects of temperature- and pressure-dependent viscosity. In order to evaluate these effects and find an improved choice for imposed plate velocity, we use a series of test models in an aspect ratio 2 domain with one variable rheology force-balanced plate.

[19] In the force balance method, the Stokes equations are solved by superposition of a kinematic solution and a noslip surface solution [Gable et al., 1991; King et al., 1992]. The kinematic solution is subject to the condition that the surface velocity must be piecewise continuous and scaled so that the integrated shear stress along a test curve near the surface is zero after superposition. This assures that there is no artificial inhibition or driving of the flow. In order to 

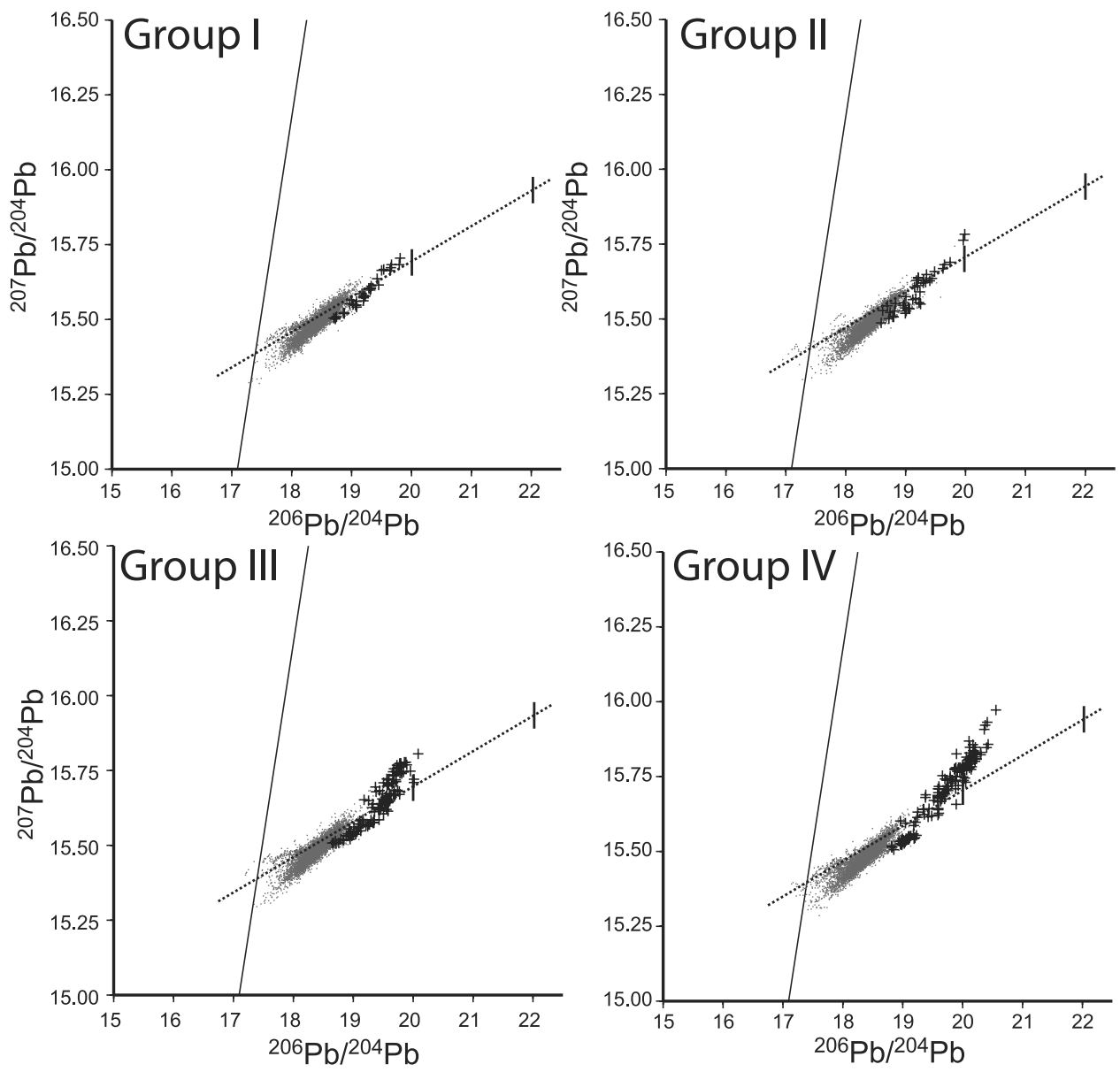

Figure 9. Grid-averaged $\mathrm{Pb}$ isotopes at 3.6 Byr for all $\mathrm{Ra}=10^{7}$ runs. The letter on each plot denotes the model group. The thin black line is the Geochron from CH94, the dashed line is the DMM-HIMU mixing line [Hofmann, 2004] with horizontal bars marking the approximate range of HIMU observations. Crosses denotes values from cells contributing to $f_{s}$, points denotes all other cells.

facilitate this method and to model the jump in viscosity at $670 \mathrm{~km}$ [Mitrovica, 1996; Mitrovica and Forte, 1997] we replace the smooth depth dependence in the $\mathrm{CH} 94$ viscosity formulation with a layered structure,

$$
\begin{aligned}
& \eta=\eta_{r}(z) \exp [-b(c T-0.5)] \\
& \text { with }\left\{\begin{array}{l}
\eta_{r}(z)=1, c=0, z<z_{l} \\
\eta_{r}(z)=1, c=1, z_{l}<z<z_{670} . \\
\eta_{r}(z)=30, c=1, z>z_{670}
\end{array}\right.
\end{aligned}
$$

Here $z_{l}$ is the nondimensional depth of the lithosphere, and $b=\ln (65,536)$. The test curve is placed at $z_{l}$, which is made to coincide with a continuous row of mesh nodes for maximum accuracy. Our implementation of the force balance method compares well with published benchmarks [Koglin et al., 2005]. Test modeling is conducted for a variety of $R a$ and $Q=7.5$ until transients from the initial condition have died away. The average, minimum, and maximum values for the plate velocity are then computed (Figure 4a). We find higher plate velocities at low $R a$ and a more gradual increase with $\mathrm{Ra}$ than $\mathrm{CH} 94$. Two values for $z_{l}$ are tested: 0.05 (thick lithosphere) and 0.03 (thin lithosphere). At the lowest $R a$, the thick lithosphere yields the higher plate velocity. As $R a$ was increased, it is overtaken by the thin lithosphere model. Ideally, every $R a$ has an optimum $z_{l}$. However, our investigations of the force balance method have shown that the difference is only a few percent and that all reasonable choices for $z_{l}$ scale with approximately the same power law constant. As in equation (11), the dimensionalization of timescales with the plate velocity. Using $u_{o}$ from our test model, a new transit timescaling is determined (Figure 4b). As an internal verification of this scaling, the transit timescale meets the diffusional timescale (where time is scaled by $\kappa / h^{2}$ ) at $R a \approx 1.5 \cdot 10^{7}$ where surface velocities are similar to Earth values. It would be ideal to directly use the force balanced plates in the full thermochemical model. However, the plate velocities in the force balance model are not steady, often spiking in response to surges in convection deeper in the mantle. This makes it considerably more difficult to scale time to plate velocity, and such a calculation would only be useful at full convective vigor where the diffusional timescale can be used.

[20] We estimate the thickness of the surface thermal boundary layer in the force-balance test models by measuring the depth to an arbitrary isotherm near the midpoint of the model. We find that the thermal boundary layer thickness varies as $R a^{-\frac{1}{5}}$. CH94 scaled the depth of melting $\left(z_{m}\right)$ to the thermal boundary layer thickness and the thickness of 

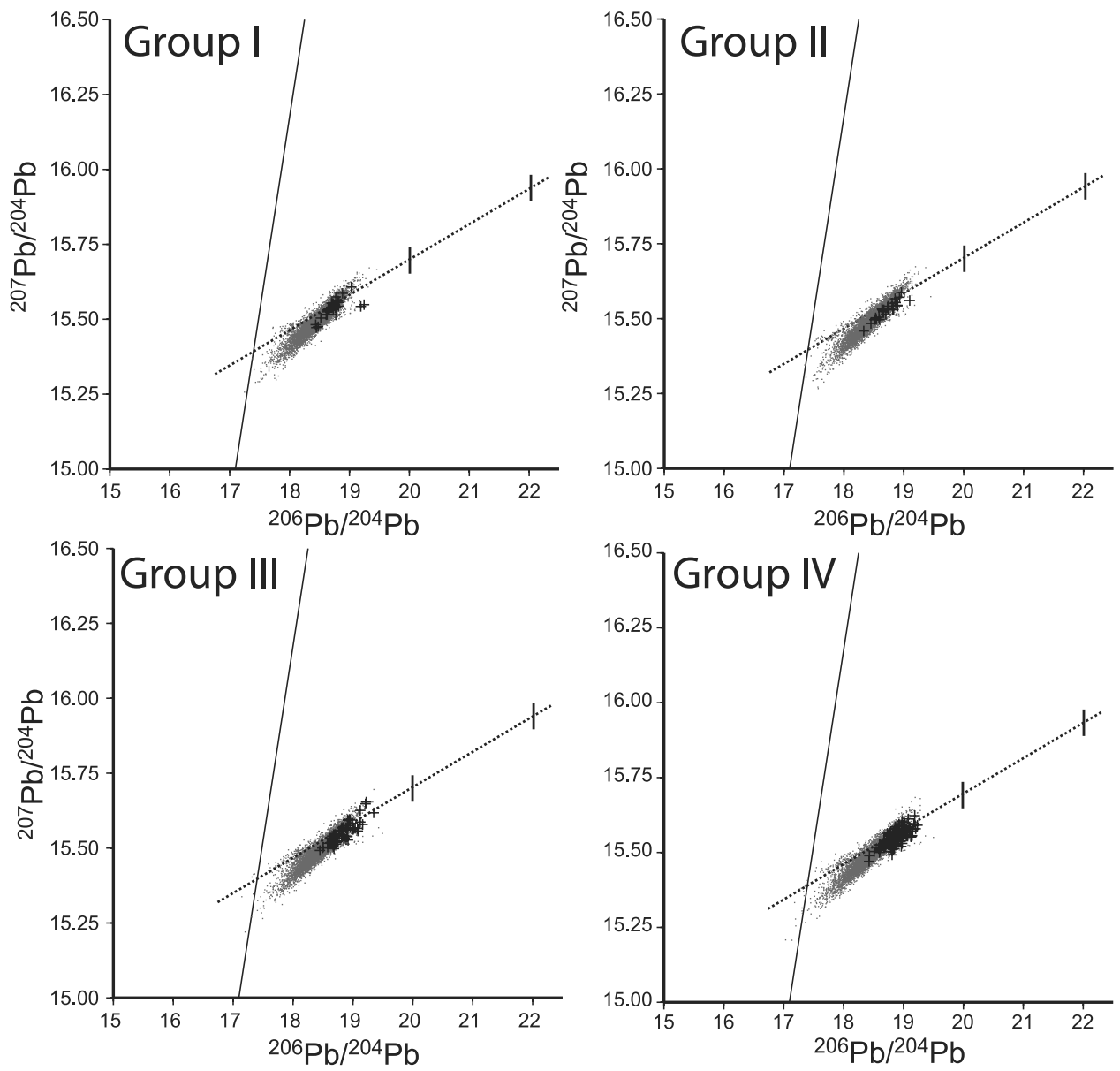

Figure 10. Grid-averaged $\mathrm{Pb}$ isotopes at $3.6 \mathrm{Byr}$ for all $\mathrm{Ra}=2 \cdot 10^{7}$ runs. The letter on each plot denotes the model group. The thin black line is the Geochron from CH94, the dashed line is the DMMHIMU mixing line [Hofmann, 2004] with horizontal bars marking the approximate range of HIMU observations. Crosses denotes values from cells contributing to $f_{s}$, points denotes all other cells.

the crust $\left(z_{c}\right)$ as $12.5 \%$ of $z_{m}$. This results in a several hundred kilometers thick crust in STD. As Ra is increased, $z_{m}$ and $z_{c}$ decrease with the thinning boundary layers. We apply $z_{m}=0.08$ at $\mathrm{Ra}=10^{5}$, and decrease the value with the scaling measured in the test models (Figure 4c). The dimensional crust thickness at $R a=2 \cdot 10^{7}$ is approximately $10 \mathrm{~km}$, which compares well to the thickness of oceanic crust.

\section{Results}

[21] Using our revised scaling laws, we investigate 32 parameter combinations with our revised $u_{o}, \mathrm{t}, z_{m}$ and $z_{c}$ scaling. These consist of four groups (I-IV) distinguished by the core-mantle boundary value of $R_{\rho}$ (Figure 1 ). In addition to our modification of the $\mathrm{CH} 94$ viscosity law and internal heating, we also vary thermal diffusivity as $\kappa(z)=$ $e^{\frac{3}{2} z}$ (Figure 1d). These changes in viscosity and conductivity lead to more sluggish convection in the lower mantle. This enhances the conditions favorable to crustal segregation.

\subsection{Dynamics}

[22] For Group I, $R_{\rho}=1.5$ at the core-mantle boundary and the trench migrates at the full rate prescribed by $\mathrm{CH} 94$.
This set of experiments is designed to be a direct extension of $\mathrm{CH} 94$. However, the small offset in $R_{\rho}$ is not taken into account so that the relative density of basalt at the coremantle boundary is slightly lower. At $R a=10^{6}$ the accumulation of crust is anomalously low. The authenticity of this is confirmed by tests at slightly lower and higher values of $\mathrm{Ra}$. There is a resonance in the system at this value that causes the accumulating crust to be swept up the side boundaries and remixed in the asthenosphere. This effect only occurs at lower $R a$ where the flow is dominated by the relatively thick slab. At and above $\mathrm{Ra}=10^{7}$ there is little to no accumulation of crust.

[23] In Group II, $R_{\rho}=1.5$ at the core-mantle boundary, and the trench migration is slowed by $50 \%$. Previous studies have identified the possibility that the relatively high rate of trench migration in the $\mathrm{CH} 94$ formulation could disrupt the formation of high-viscosity segregated areas of the mantle [Davies, 2002]. This set of experiments is conducted at a slower trench migration in order to examine the effect of trench migration on crustal segregation. For $R a<10^{6}$, the amount of crustal segregation is generally less than corresponding models with full trench migration. When convective vigor is low the slab has a tendency to impinge directly on the CMB and sweep segregated crust back into 


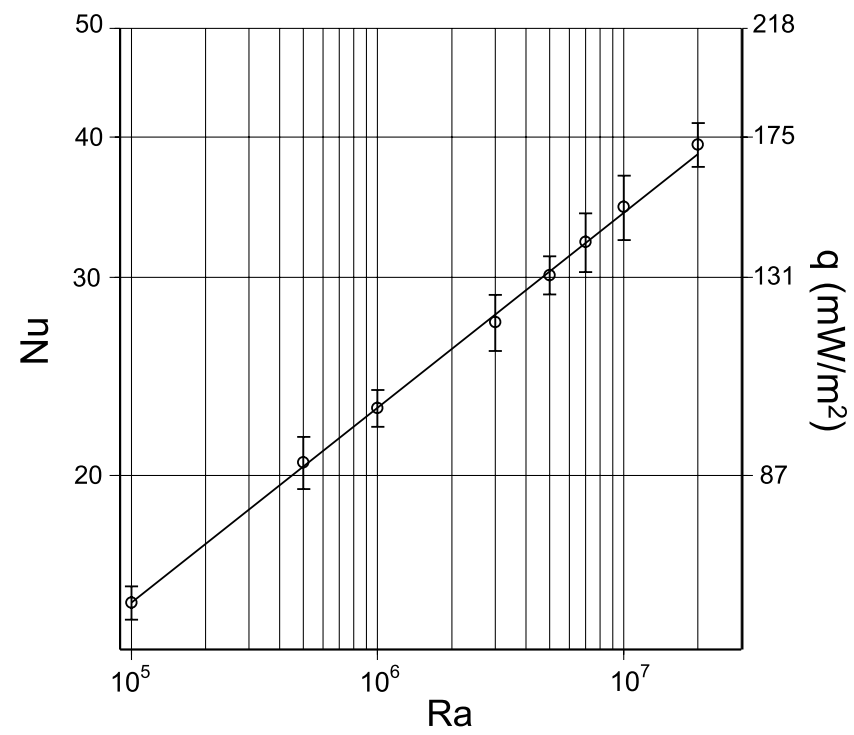

Figure 11. Scaling of heat flow with convective vigor for Group A models. Error bars indicate maximum fluctuation in heat flow over the entire 3.6 Byr model run.

the mantle. Reducing the trench migration rate enhances this effect. Above $R a=10^{6}$ the convective vigor is high enough that sections of the slab break free and settle to the $\mathrm{CMB}$ without causing this disruption. Between $R a=10^{6}$ and $R a=$ $10^{7}$, the amount of segregation is higher than in corresponding full trench migration rate models. At $\mathrm{Ra}=$ $10^{7}$ and above the amount of segregation is approximately the same (see Figure 13 in section 4). This suggests that the trench migration rate causes some enhanced mixing when convective vigor is low, but has only a small influence when convective vigor reaches realistic values.

[24] For Group III, $R_{\rho}=2.0$ at the core-mantle boundary and the trench migrates at the full rate. Significant accumulation of crust at the core-mantle boundary persists until $\mathrm{Ra}=10^{7}$. Finally, for Group IV, the value of $R_{\rho}$ is 2.5 at the core-mantle boundary. The trench migrates at the full rate. Significant accumulation of crust at the core-mantle boundary persists and remains robust for all Ra. The tendrils of eclogite entrained by thermal plumes display interesting thermochemical behavior at high $R a$ as thin layers of harzburgite trapped in the accumulated crust interfinger with sinking eclogite (Figure 5). At all $R a$ there are noticeable accumulations of eclogite just above the viscosity jump.

\subsection{Isotopic Composition}

[25] In the lower convective vigor models, the spread of isotopic values at 3.6 Byr is considerable (Figure 6). In the $\mathrm{Pb}-\mathrm{U}$ system, a significant number of sampling grid cells have isotopic ratios that plot to the left of the geochron. These cells are sampling the portion of the mantle depleted by partial melting. At higher $R a$, the depleted mantle and enriched crust are mixed to smaller length scales and the $\mathrm{Pb}$ ratios are dominated by the more highly fractionated eclogite (Figure 7). However, the values to the left of the geochron are largely influenced by the artificially high $\mathrm{Pb}$ partition coefficient used in these calculations. Rather than constituting a "missing $\mathrm{Pb}$ " reservoir that is obscured by mixing with HIMU mantle, these values reflect areas of the mantle excessively depleted in $\mathrm{U}$ relative to $\mathrm{Pb}$. Models in the range of $R a=7 \cdot 10^{6}$ have a similar spread of isotopic ratios, but lack any significant values left of the geochron (Figure 8). The models at this convective vigor also have a realistic spread of values in $\mathrm{Nd}-\mathrm{Pb}$ isotopic space, clearly demonstrating mixing between a DMM and HIMU component (Figure 7).

[26] Even though the slopes in isotope space remain the same, the distinct end-members begin to disappear with further increase in the convective vigor. At $R a=10^{7}$, the HIMU and DMM components are only present for Group III and IV models $\left(R_{\rho}=2.0\right.$ and 2.5, Figure 9). At $R a=2 \cdot 10^{7}$ mixing is highly efficient and the end-members are no longer present, at least not on a length scale that can be sampled by the grid (Figure 10).

\section{Discussion}

[27] As our models are scaled to increasing convective vigor, the thermal boundary layers become progressively thinner. This changes the temperature gradient, and therefore the heat flow. The heat flow in these models scales as $R a^{0.17}$ (Figure 11). Compared to the average oceanic value of $100 \mathrm{~mW} / \mathrm{m}^{2}$ [Pollack et al., 1993], all models with $\mathrm{Ra}>3 \cdot 10^{6}$ produce satisfactory heat flow. However, the surface velocity is too low for $\mathrm{Ra}<7 \cdot 10^{6}$ [Ullrich and van der Voo, 1981; Gordon, 1998]. The models with satisfactory surface velocities therefore have a heat flow that is approximately $150 \%$ of the oceanic value. Models with a Cartesian geometry tend to overestimate the amount of heat entering the base and underestimate the amount of surface cooling, leading to elevated heat flow [Jarvis, 1994; van Keken, 2001]. We assume in this case that Earth-like convective vigor is indicated by $u_{o}>3 \mathrm{~cm} / \mathrm{a}$, which is reached at $R a>5 \cdot 10^{6}$.

[28] The mode of heating in our models varies from approximately $80 \%$ internal heating at low convective vigor to $50 \%$ at realistic convective vigor. Estimates for the mantle based on plume buoyancy flux are smaller, with CMB heat flux possibly accounting for as little as $10 \%$ of the surface heat flow [Davies, 1988; Sleep, 1990]. The use of a two-dimensional approximation may further enhance the role of basal heating by exaggerating the effects of thermal plumes [Davies, 2002]. However, heating of the mantle from the cooling core is a complicated and uncertain process. For example, more accurate calculations of temperatures within the core [e.g., Steinle-Neumann et al., 2001] have revealed that the temperature contrast across the $\mathrm{CMB}$ is likely larger than estimated from plume buoyancy flux. Including core cooling in geodynamic models is also source of uncertainty, as it has been found that the scaling of basal heat flux is not constant with increasing Rayleigh number and may depend considerably on the model boundary conditions [Zhong, 2005]. Our estimate of the relative amount of basal heating is based on the quasi steady state initial conditions, and reflects only thermal convection. Once the CMB becomes blanketed with a layer of sequestered crust, the relative efficiency of basal heating decreases. This is seen as a small decrease in surface heat flux. Although we have not quantified the value here, plumes 


\section{A. $R \rho=1.5$ at $C M B$, Full trench migration velocity}

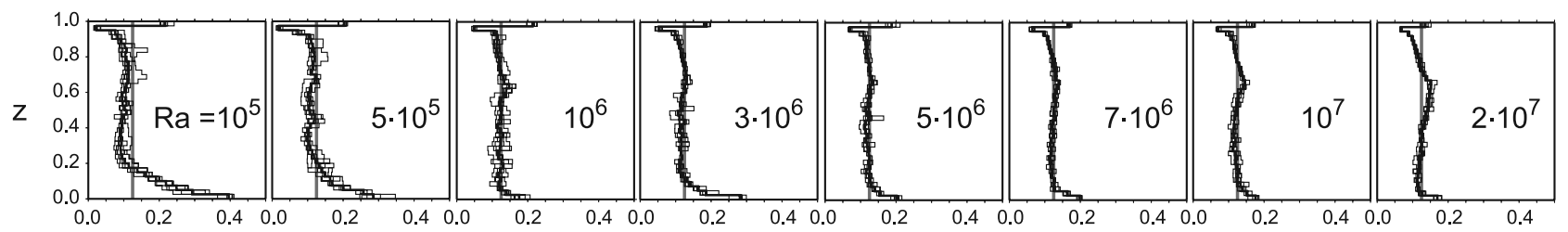

\section{B. $R \rho=1.5$ at $C M B$, Half trench migration velocity}

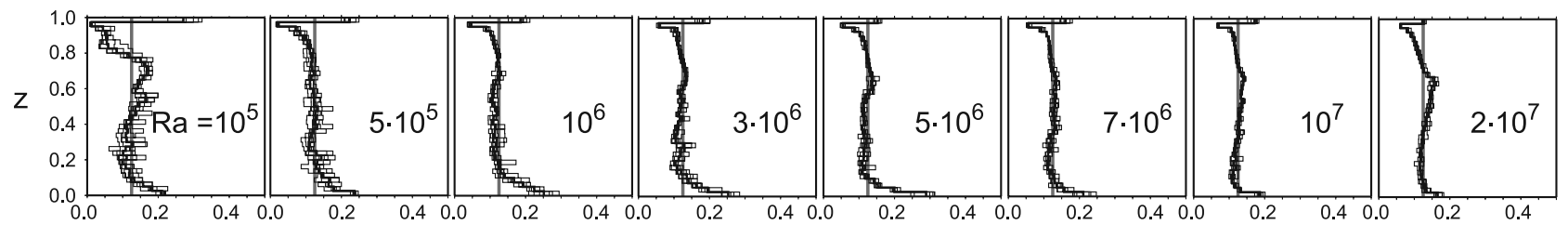

\section{C. $R \rho=2.0$ at $\mathrm{CMB}$, Full trench migration velocity}

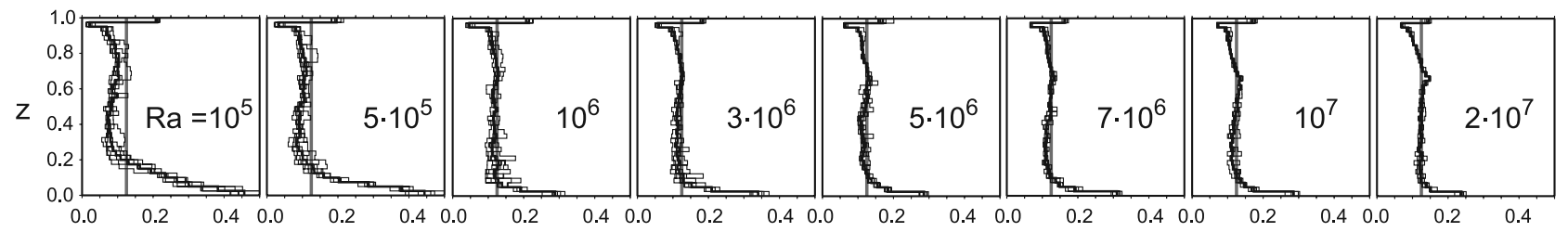

D. $R \rho=2.5$ at $C M B$, Full trench migration velocity

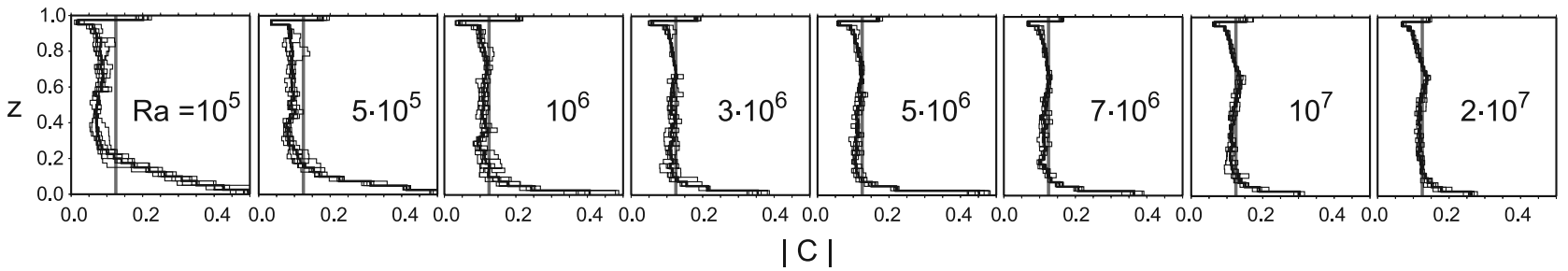

Figure 12. Profiles of the depth-averaged composition for all runs. The vertical gray line indicates $\mathrm{C}=0.125$, which is equivalent to undifferentiated mantle peridotite.

from a dense layer at the base of the mantle have been found to possess a much lower excess temperature than plumes from a purely thermal boundary layer [Farnetani, 1997]. This may in part explain the low heat flow estimates from plume buoyancy flux and further illustrates the uncertainty in mantle heating.

[29] The initial focus of this study is directed at the layer of pooled eclogite. Davies [2002] used radial averaging to measure crustal segregation and detect stratification. This computation is included here. We determine an average $C$ value for each horizontal row of cells in our sampling grid at $48 \mathrm{Ma}$ intervals over the last $240 \mathrm{Ma}$ of each experiment. The resulting profiles are displayed in Figure 12. All profiles have two characteristics in common: a zone of high $\mathrm{C}$ just above the core-mantle boundary, and a $\mathrm{C}$ gradient in the upper mantle. The low $\mathrm{C}$ values in the upper mantle gradient are created by the depletion of the upper mantle and the enrichment of the crust. Davies [2002] and Xie and Tackley [2004] observed a similar upper mantle settling effect. A similar effect has also been proposed as a possible mechanism for the depletion of the upper mantle in the hotter young Earth [Davies, 2006]. The high $\mathrm{C}$ values near the bottom of the upper mantle are due to eclogite accumulation between the depleted upper mantle and the viscosity jump at $670 \mathrm{~km}$. This effect is most pronounced at the highest $\mathrm{Ra}$ studied. In particular, the $\mathrm{Ra}=2 \cdot 10^{7}$ results from groups I, II and III lack significant eclogite pooling at the core-mantle boundary but have a well defined midmantle accumulation. However, the $\mathrm{Ra}=2 \cdot 10^{7}$ results do demonstrate significant $\mathrm{CMB}$ accumulation when $R_{\rho}$ is increased.

[30] As in the reproduction of STD from CH94, $\mathrm{f}_{\mathrm{s}}$ remains a highly variable measurement in these models. CH94 predicted a sharp but predictable decrease with increasing $\mathrm{Ra}$ based on three results. We find much more variation, particularly at low $R a$. In our results that we deem to be in the regime of terrestrial mantle convection $\left(5 \cdot 10^{6}-\right.$ $2 \cdot 10^{7}$ ), the variation is more systematic (Figure 13). The eclogite accumulation is significant in many, but not all of the results from this range. This is consistent with the accumulation in the results of Davies [2002] and Xie and Tackley [2004], but demonstrates that such large accumulations won't necessarily form for all combinations of model parameters. 


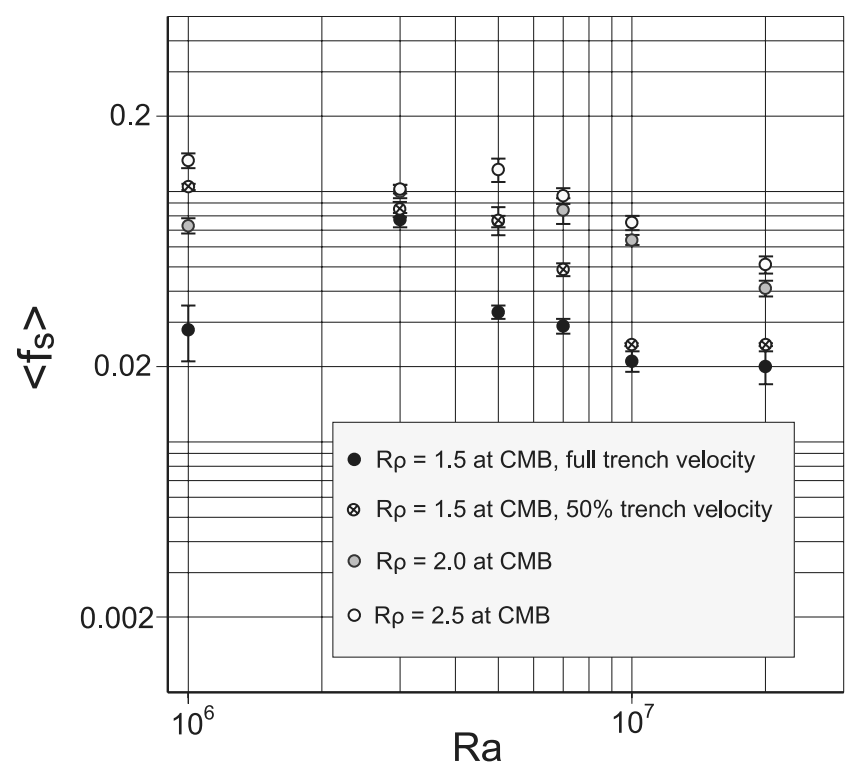

Figure 13. Fraction of pooled eclogite tracers as a function of $R a$ and the core-mantle boundary value of $R_{\rho}$. The average is taken over the last 0.24 Byr of the model run, and error bars indicate the maximum fluctuation of $\mathrm{f}_{\mathrm{s}}$ during that time.

[31] The force balance method is a consistent robust approximation to plate-like behavior and is used in many contemporary models [Monnereau and Quéré, 2001; Lowman et al., 2001,2003]. Strong plates may contribute substantially to the development of chemical heterogeneity in the mantle [Ogawa, 2003] and should not be neglected. Ideally, we would apply the force balance condition with the thermochemical computations in addition to the thermal test experiments. However, a set of pilot models revealed that the plates were subject to reversals initiated by the migrating trench. This is an effect observed in most models with force balanced plates and strong internal heating [King et al., 2002; Lowman et al., 2003]. Moreover, rapidly changing plate velocities would make the use of the transit time scaling less meaningful. It may be possible to address this problem by expanding the melting formulation to a more generic treatment and seeking an alternative time scaling for intermediate Ra results, but such modifications are beyond the scope of this study. In addition to the force balance method, there are a number of techniques for simulating plate like behavior in a dynamically consistent way [Tackley, 1998; Trompert and Hansen, 1998]. Simulating the lithosphere as a non-Newtonian layer has been applied in thermochemical models that use the isotopic composition model developed in CH94 [Xie and Tackley, 2004]. We use the force balance boundary condition to simplify the dynamics of the model as much as possible in order to focus on the development of dynamic scaling laws.

[32] Our results demonstrate that within a realistic range of dynamic parameters, segregation of oceanic crust at realistic convective vigor does not necessarily lead to the development of a large-scale HIMU reservoir at the base of the mantle. Within the range of models that yield appropriately high surface velocities there is a considerable variation in the presence of the HIMU end-member. At $R a=10^{7} \mathrm{a}$ small population of HIMU sampling cells is observed at the CMB only when eclogite has an elevated excess density in the lower mantle (Figure 9). At $R a=2 \cdot 10^{7}$ the mantle is isotopically homogeneous (Figure 10) on the scale of our sampling grid. However, the amount of sequestered crust is not significantly less than observed in lower vigor models with a robust population of HIMU sampling cells at the CMB (e.g., $R a=7 \cdot 10^{6}$, Figures 7 and 13). Therefore CMB sequestration becomes dramatically less efficient at isolating subducted crust from convective mixing as convective vigor approaches realistic values. The size of the accumulations may remain large, but the residence time of old crust in the accumulations is similar to residence times elsewhere in the mantle. In order for a HIMU reservoir to develop in our models it is necessary to minimize the relative convective vigor of the lowermost mantle, thus extending the residence time of sequestered crust. Within the parameter space that we explore, this is only accomplished with a reduced Rayleigh number and extended time scaling similar to that used by $\mathrm{CH} 94$.

[33] In addition to dynamic processes, the diminishing prominence of a HIMU signature with increasing Ra may reveal some limitations of this geochemical modeling approach. As convective vigor increases toward realistic values, many convective features develop a much finer length scale and become more convoluted. However, we maintain a constant spacing in our isotope sampling grid so that $\langle f s\rangle$ is calculated consistently. It may be necessary to systematically decrease the size of the sampling grid to resolve the increasing level of detail and recover the spread of isotope values seen at lower Ra. A systematic analysis of this problem could potentially answer some of the unresolved questions concerning the selection of an appropriate isotope sampling grid [Xie and Tackley, 2004]. Davies [2002] argued that sampling isotopes over the volume of the mantle is inappropriate for exactly these reasons.

[34] The lack of a distinct HIMU reservoir at realistic convective vigor suggests that it may be pertinent to consider other mechanisms. Xie and Tackley [2004] found that a thin layer of eclogite with a HIMU-like isotopic composition developed just above the $670-\mathrm{km}$ phase transition in their model. We do not explicitly account for phase transitions, but also find a similar enriched layer just above the viscosity jump (Figure 12). This layer increases in density and becomes more pronounced with increasing convective vigor. Although it is below the resolution of our sampling grid, this area of the mantle could potentially host a number of small HIMU anomalies. Such a large-scale highly heterogeneous reservoir is consistent with mass balance calculations for the ocean island basalt mantle source [Kellogg et al., 2002].

[35] It is also possible that the large-scale HIMU source may reside in a reservoir of greater antiquity. The survival and dynamics of an ancient dense layer has been the focus for a number of geodynamic studies [e.g., Montague and Kellogg, 2000; Tackley, 2002; Oldham and Davies, 2004; McNamara and Zhong, 2004]. Such a preexisting layer can survive for a considerable amount of time with a density contrast of a few percent, and will likely be swept into local concentrations by impinging slabs [McNamara and Zhong, 2005]. Seismic tomography has revealed the presence of such large-scale structures in the lower mantle [Ritsema et 
al., 1999] which have some seismic characteristics suggestive of an inherent excess chemical density [Ni and Helmberger, 2003]. If this dense layer contains some portion of ancient oceanic crust [van Thienen et al., 2004] then it could potentially serve as a large-scale source of HIMU mantle as well as primordial noble gases [Kellogg et al., 1999]. Including an ancient dense layer in our models could potentially increase the residence time of crust at the CMB since it would eliminate the period of accumulation when entrainment is the highest.

\section{Conclusions}

[36] We revisit the work of $\mathrm{CH} 94$ and extend the models to more Earth-like convective vigor. Careful reproduction of the $\mathrm{CH} 94$ base model reveals that the fraction of pooled eclogite is highly sensitive to small changes in the ratio between thermal and chemical buoyancy in the lower mantle. When approximately 888,000 active tracers are used, a grid with 4000-10,000 cells is essential for reproducible sampling of this layer. We find that an increase in the value of the phase-buoyancy ratio for the lower mantle is essential for the eclogite layer to persist and develop a HIMU isotopic signature at high Rayleigh number. At the highest convective vigor analyzed $\left(R a=2 \cdot 10^{7}\right)$, sufficient lower mantle buoyancy did allow an eclogite layer to form. However, even with this provision no HIMU component was observed in the $R a=2 \cdot 10^{7}$ results. This may be due to either a dramatic decrease in mixing length scale, or too short of a residence time in the layer. Analysis of the radially averaged composition reveals significant stratification of the upper mantle in all results.

[37] Acknowledgments. We thank Chris Ballentine, Erik Hauri, and Ulrich Christensen for their helpful discussion, and we thank Geoff Davies, Garrett Ito, and John Mahoney for their constructive reviews. This research was supported by the National Science Foundation.

\section{References}

Aoki, I., and E. Takahashi (2004), Density of MORB eclogite in the upper mantle, Phys. Earth Planet. Int., 143-144, 129-143.

Blankenbach, B., et al. (1989), A benchmark comparison for mantle convection codes, Geophys. J. Int., 98, 23-38.

Carlson, R. W. (1994), Mechanisms of Earth differentiation: Consequences for the chemical structure of the mantle, Rev. Geophys., 32(4), 337-361.

Christensen, U. R. (2001), Geodynamic models of deep subduction, Phys. Earth Planet. Int., 127, 25-34.

Christensen, U. R., and A. W. Hofmann (1994), Segregation of subducted oceanic crust in the convecting mantle, J. Geophys. Res., 99(B10), $19,867-19,844$.

Davies, G. F. (1984), Geophysical and isotopic constraints on mantle convection: An interim thesis, J. Geophys. Res., 89(B7), 6017-6040.

Davies, G. F. (1988), Ocean bathymetry and mantle convection: 1. Largescale flow and hotspots, J. Geophys. Res., 93(B9), 10,467-10,480.

Davies, G. F. (2002), Stirring geochemistry in mantle convection models with stiff plates and slabs, Geochim. Cosmochim. Acta, 66(17), 31253142.

Davies, G. F. (2006), Gravitational depletion of the early Earth's upper mantle and the viability of early plate tectonics, Earth Planet. Sci. Lett., $243,376-382$.

Farnetani, C. G. (1997), Excess temperature of mantle plumes: The role of chemical stratification across D", Geophys. Res. Lett., 24(13), 15831586.

Gable, C. W., R. J. O'Connell, and B. J. Travis (1991), Convection in three dimensions with surface plates: Generation of a toroidal flow, J. Geophys. Res., 96(B5), 8391-8405

Gordon, R. G. (1998), The plate tectonic approximation: plate non-rigidity, diffuse plate boundaries, and global plate reconstructions, Аnпи. Rev. Earth Planet. Sci., 26, 615-642.
Hart, S. R. (1988), Heterogeneous mantle domains: Signatures, genesis and mixing chronologies, Earth Planet. Sci. Lett., 90, 273-296.

Hirose, K., N. Takafuji, N. Sata, and Y. Ohishi (2005), Phase transition and density of subducted MORB crust in the lower mantle, Earth Planet. Sci. Lett., 237, 239-251.

Hofmann, A. W. (2004), Sampling mantle heterogeneity through oceanic basalts: Isotopes and trace elements, in Treatise on Geochemistry, vol. 2 , The Mantle and Core, edited by H. D. Holland and K. K. Turekian, pp. 61-97, Elsevier, New York.

Hofmann, A. W., and W. M. White (1982), Mantle plumes from ancient oceanic crust, Earth Planet. Sci. Lett., 57, 421-436.

Irifune, T., and A. E. Ringwood (1993), Phase transformation in subducted oceanic crust and buoyancy relationships at depths of $600-800 \mathrm{~km}$ in the mantle, Earth. Planet. Sci. Lett., 117, 101-110.

Jarvis, G. T. (1994), The unifying role of aspect ratio in cylindrical models of mantle convection with varying degrees of curvature, Geophys. J. Int., $117,419-426$.

Kellogg, J. B., S. B. Jacobsen, and R. J. O'Connell (2002), Modeling the distribution of isotopic ratios in geochemical reservoirs, Earth Planet. Sci. Lett., 204, 183-202.

Kellogg, L. H., B. H. Hager, and R. D. van der Hilst (1999), Compositional stratification in the deep mantle, Science, 283, 1881-1884.

Kesson, S. E. J. D. Fitz Gerald, and J. M. G. Shelley (1994), Mineral chemistry and density of subducted basaltic crust at lower mantle pressures, Nature, 372, 767-769.

King, S. D., C. W. Gable, and S. A. Weinstein (1992), Models of convection-driven tectonic plates: A comparison of methods and results, Geophys. J. Int., 109, 481-487.

King, S. D., J. P. Lowman, and C. W. Gable (2002), Episodic tectonic plate reorganizations driven by mantle convection, Earth Planet. Sci. Lett., 203, 83-91.

Koglin, D. E., Jr., S. R. Ghias, S. D. King, G. T. Jarvis, and J. P. Lowman (2005), Mantle convection with reversing mobile plates: A benchmark study, Geochem. Geophys. Geosyst., 6, Q09003, doi:10.1029/ 2005GC000924.

Lowman, J. P., S. D. King, and C. W. Gable (2001), The influence of tectonic plates on mantle convection patterns, temperature and heat flow, Geophys. J. Int., 146, 619-636.

Lowman, J. P., S. D. King, and C. W. Gable (2003), The role of the heating mode of the mantle in intermittent reorganization of the plate velocity field, Geophys. J. Int., 152, 455-467.

McNamara, A. K., and S. Zhong (2004), Thermochemical structures within a spherical mantle: Superplumes or piles?, J. Geophys. Res., 109, B07402, doi:10.1029/2003JB002847.

McNamara, A. K., and S. Zhong (2005), Thermochemical structures beneath African and the Pacific Ocean, Nature, 473, 1136-1139.

Mitrovica, J. X. (1996), Haskell [1935] revisited, J. Geophys. Res., 101(B1), 555-569.

Mitrovica, J. X., and A. M. Forte (1997), Radial profile of mantle viscosity: Results from the joint inversion of convection and postglacial rebound observations, J. Geophys. Res., 102(B2), 2751-2769.

Monnereau, M., and S. Quéré (2001), Spherical shell models of mantle convection with tectonic plates, Earth Planet. Sci. Lett., 184, 575-587.

Montague, N. L., and L. H. Kellogg (2000), Numerical models of a dense layer at the base of the mantle and implications for the dynamics of $\mathrm{D}^{\prime \prime}$, J. Geophys. Res., 105(B5), 11,101-11,114.

Newsom, H. E., W. M. White, K. P. Jochum, and A. W. Hofmann (1986) Siderophile and chalcophile element abundances in oceanic basalts, $\mathrm{Pb}$ isotope evolution and growth of the Earth's core, Earth Planet. Sci. Lett., $80,299-313$

Ni, S., and D. V. Helmberger (2003), Seismological constraints on the South African superplume; could be the oldest distinct structure on Earth, Earth Planet. Sci. Lett., 206, 119-131.

Ogawa, M. (2003), Chemical stratification in a two-dimensional convecting mantle with magmatism and moving plates, J. Geophys. Res., 108(B12), 2561, doi: $10.1029 / 2002 J B 002205$

Oldham, D., and J. H. Davies (2004), Numerical investigation of layered convection in a three-dimensional shell with applications to planetary mantles, Geochem. Geophys. Geosyst., 5, Q12C04, doi:10.1029/ 2003GC000603

Ono, S., E. Ito, and T. Katsura (2001), Mineralogy of subducted basaltic crust (MORB) from 25 to $37 \mathrm{GPa}$, and chemical heterogeneity in the lower mantle, Earth Planet. Sci. Lett., 190, 57-63.

Phipps-Morgan, J., and W. J. Morgan (1999), Two-stage melting and the geochemical evolution of the mantle: a recipe for mantle plum-pudding, Earth Planet. Sci. Lett., 170, 215-239.

Poli, S., and M. W. Schmidt (2002), Petrology of subducted slabs, Аnпи. Rev. Earth Planet. Sci., 30, 207-235. 
Pollack, H. N., S. J. Hurter, and J. R. Johnson (1993), Heat flow from the Earth's interior: Analysis of the global data set, Rev. Geophys., 31(3), $267-280$.

Ritsema, J., H. J. van Heijst, and J. H. Woodhouse (1999), Complex shear wave velocity structure imaged beneath Africa and Iceland, Science, 286, $1925-1928$

Segal, G., and N. P. Praagman (1995), Sepran user's guide, report, Tech. Univ. of Delft, Delft, Netherlands.

Silver, P. G., R. W. Carlson, and P. Olson (1988), Deep slabs, geochemical heterogeneity, and the large scale structure of mantle convection: Investigation of and enduring paradox, Annu. Rev. Earth Planet. Sci., 16, $477-$ 541.

Sleep, N. H. (1990), Hotspots and mantle plumes: Some phenomenology, J. Geophys. Res., 95(B5), 6715-6736.

Steinle-Neumann, G., L. Stixrude, R. E. Cohen, and O. Gülseren (2001), Elasticity of iron at the temperature of the inner core, Nature, 413, 5760

Tackley, P. J. (1998), Self-consistent generation of tectonic plates in threedimensional mantle convection, Earth Planet. Sci. Lett., 157, 9-22.

Tackley, P. J. (2000), Mantle convection and plate tectonics: toward an integrated physical and chemical theory, Science, 288, 2002-2007.

Tackley, P. J. (2002), Strong heterogeneity caused by deep mantle layering, Geochem. Geophys. Geosyst., 3(4), 1024, doi:10.1029/2001GC000167.

Tackley, P. J., and S. D. King (2003), Testing the tracer ratio method for modeling active compositional fields in mantle convection simulations, Geochem. Geophys. Geosyst., 4(4), 8302, doi:10.1029/2001GC000214.

Tackley, P. J., and S. Xie (2002), The thermochemical structure and evolution of Earth's mantle: Constraints and numerical models, Philos. Trans. R. Soc., Ser. A, 360, 2539-2606.

Trompert, R., and U. Hansen (1998), Mantle convection simulations with rheologies that generate plate-like behavior, Nature, 395, 686-689.
Turcotte, D. L., and G. Schubert (2002), Geodynamics, 2nd ed., 456 pp., Cambridge Univ. Press, New York.

Ullrich, L., and R. van der Voo (1981), Minimum continental velocities with respect to the pole since the Archean, Tectonophysics, 74, 17-27.

van Keken, P. E. (2001), Cylindrical scaling for dynamic cooling models of the Earth, Phys. Earth Planet. Int., 124, 119-130.

van Keken, P. E., S. D. King, H. Schmeling, U. R. Christensen, D. Neumeister, and M.-P. Doin (1997), A comparison of methods for the modeling of thermochemical convection, J. Geophys. Res., 102(B10), 22,47722,495 .

van Keken, P. E., E. H. Hauri, and C. J. Ballentine (2002), Mantle mixing: The generation, preservation, and destruction of chemical heterogeneity, Annu. Rev. Earth Planet. Sci., 30, 493-525.

van Thienen, P., A. P. van den Berg, and N. J. Vlaar (2004), Production and recycling of oceanic crust in the early Earth, Tectonophysics, 386, 41-65.

Xie, S., and P. J. Tackley (2004), Evolution of U-Pb and Sm-Nd systems in numerical models of mantle convection and plate tectonics, J. Geophys. Res., 109, B11204, doi:10.1029/2004JB003176.

Zegers, T. E., and P. E. van Keken (2001), Middle Archean continent formation by crustal delamination, Geology, 29(12), 1083-1086.

Zhong, S. (2005), Dynamics of thermal plumes in three-dimensional isoviscous thermal convection, Geophys. J. int., 162, 289-300.

Zindler, A., and S. Hart (1986), Chemical geodynamics, Annu. Rev. Earth Planet. Sci., 14, 493-571.

J. P. Brandenburg and P. E. van Keken, Department of Geological Science, University of Michigan, 2534 C.C. Little Building, Ann Arbor, MI 48109-1005, USA. (jpbrande@umich.edu) 